\title{
Impact of Increased Heart Rate Alone and Heart Rate Plus Contractility Upon Intraventricular ECG Morphology
}

\author{
Cynthia J. Finelli, MSE, Robert D. Throne, PhD, Nikolaos Antoniadis, \\ MSE, Janice M. Jenkins, PhD, Stuart A. Winston, DO, \\ and Lorenzo A. DiCarlo, MD
}

\begin{abstract}
Morphologic methods proposed for detection of ventricular tachycardia commonly use a template of averaged intraventricular ECGs acquired during sinus rhythm for comparison with ventricular tachycardia. Whether increased heart rate with and without an accompanying increase in contractility affects the stability of the intraventricular electrogram during sinus rhythm is unknown, however. We examined the intraventricular ECGs from two groups of patients undergoing electrophysiology studies before and during doses of an $\alpha$ - and $\beta$-agonist, epinephrine (group A, 13 patients, $50 \mathrm{ng} / \mathrm{kg} / \mathrm{min}$ ) and of a pure $\beta$-agonist, isoproterenol (group B, 11 patients, $2 \mu \mathrm{g} / \mathrm{min}$ ), and from four groups of patients being treated with atrial pacing at different rates (group C, 8 patients, $600 \mathrm{~ms}$; group D, 7 patients, $500 \mathrm{~ms}$; group E, 8 patients, $450 \mathrm{~ms}$; group F, 8 patients, $400 \mathrm{~ms}$ ). Sinus cycle length decreased from $776 \pm 134 \mathrm{~ms}$ to $684 \pm 146 \mathrm{~ms}$ in group $\mathrm{A}$; from $733 \pm 117$ to $519 \pm 54 \mathrm{~ms}$ in group $B$; from 796 $\pm 90 \mathrm{~ms}$ to $603 \pm 2 \mathrm{~ms}$ in group C; from $756 \pm$ $129 \mathrm{~ms}$ to $502 \pm 2 \mathrm{~ms}$ in group D; from $720 \pm 136$ $\mathrm{ms}$ to $452 \pm 1 \mathrm{~ms}$ in group E; and from $714 \pm 153$ $\mathrm{ms}$ to $402 \pm 2 \mathrm{~ms}$ in group F. Correlation waveform analysis was performed on ventricular ECGs recorded from bipolar RV apex electrodes $(1 \mathrm{~cm}, \mathrm{I}-$ $500 \mathrm{~Hz}$ ) using a best fit method of alignment of depolarization. When compared to a control passage
\end{abstract}

From the Department of Electrical Engineering and Computer Science, the University of Michigan and St. Joseph Mercy Hospital, Ann Arbor, Michigan.

Supported in part by NSF Grant BCS-8909042 and by Cardiac Pacemakers, Inc.

Reprint requests: Cynthia J. Finclli, Mcdical Computing Laboratory, Department of Electrical Engineering and Computer Science, The University of Michigan, Ann Arbor, MI 48109-2122. of sinus rhythm before drug administration, the mean correlation coefficient decreased by $0.0 \%$ to $2.1 \%$ in 12 of 13 patients and $9.4 \%$ in 1 patient during epinephrine administration. It decreased by $0.0-$ $1.4 \%$ in 9 of 11 patients during isoproterenol therapy and by $20.2 \%$ and $21.6 \%$ in the 2 other patients. When compared to a sinus rhythm control passage before atrial pacing intervention, the mean correlation coefficient decreased by $0.0 \%$ to $2.3 \%$ in 8 of 8 patients with a pacing rate of $600 \mathrm{~ms}$; by $-0.2 \%$ to $1.4 \%$ in 7 of 7 patients paced at a rate of $500 \mathrm{~ms}$; by $0.0 \%$ to $2.0 \%$ in all 8 patients with a pacing rate of $450 \mathrm{~ms}$; and by $0.5 \%$ to $2.3 \%$ in the 8 patients being paced at a rate of $400 \mathrm{~ms}$.

\section{Conclusions}

During sinus rhythm, intraventricular ECG morphology appears to remain stable in the presence of epinephrine and isoproterenol in most patients. However, the template representing sinus rhythm may require updating in some patients due to changes in sympathetic tone. During pacing intervention, our results indicate that the morphology of the intraventricular ECG remains unchanged. 